\title{
Imaging cardiac dyssynchrony
}

\author{
Serge D. Van Kriekinge • Guido Germano
}

Received: 1 August 2013/Accepted: 20 September 2013/Published online: 22 October 2013

(C) Italian Association of Nuclear Medicine and Molecular Imaging 2013

\begin{abstract}
Myocardial perfusion imaging (MPI) has become a preeminent molecular imaging technique to assess ventricular mechanical dyssynchrony. In this article, we outline the motivation for the assessment of dyssynchrony, briefly review the application of echocardiographic and other non-nuclear imaging techniques for that purpose, and detail the technical aspects and validation of phase analysis by gated single-photon computed emission tomography and positron emission tomography. We also briefly outline differences between phase analysis of MPI and radionuclide angiography. Clinical applications are then reviewed, focusing on cardiac resynchronization therapy.
\end{abstract}

Keywords Dyssynchrony · Cardiac

resynchronization therapy - Phase analysis .

Myocardial perfusion imaging

\section{Introduction}

Systolic mechanical dyssynchrony of the left ventricle (LV) is commonly defined as the lack, to a varying degree, of synchronous contraction of the myocardium. Impaired systolic function results from dyssynchrony: as regions of

Color figures online at http://link.springer.com/article/10.1007/ s40336-013-0036-9.

S. D. Van Kriekinge $(\bowtie) \cdot$ G. Germano

Artificial Intelligence in Medicine, Cedars-Sinai Medical Center, 8700 Beverly Blvd., Ste A047N, Los Angeles, CA 90048, USA e-mail: vankriekinges@cshs.org

G. Germano

David Geffen School of Medicine, University of California, Los Angeles, CA, USA the myocardium contract at different times instead of simultaneously, hemodynamics are adversely affected and a decrease in left ventricular ejection fraction (LVEF) is typically observed. Although it has been shown that electrical dyssynchrony (commonly measured as the duration of the QRS complex) and mechanical dyssynchrony are not equivalent [1], the 2008 American Heart Association (AHA) and American College of Cardiology (ACC) cardiac resynchronization therapy (CRT) eligibility guidelines only mandated sinus rhythm with prolonged QRS duration (QRS $\geq 120 \mathrm{~ms}$ ) in addition to advanced heart failure [New York Heart Association (NYHA) functional class IIIIV] and depressed systolic LV function (LVEF $\leq 35 \%$ ) [2]. CRT is a widely accepted adjunctive to optimal medical therapy for heart failure (HF) patients, and long-term response rates of approximately $70 \%$ have been reported with the above selection criteria [3, 4], where response is defined using clinical or echocardiographic parameters. Consequently, emphasis has been placed on evaluating the prognostic value of mechanical dyssynchrony in $\mathrm{HF}$ patients as well as optimizing patient selection for CRT, and it has been suggested that pre-existing mechanical LV dyssynchrony may contribute to positive response to CRT $[4,5]$. The AHA/ACC guidelines were updated in 2012 [6] with new recommendations for patients in NYHA class II and LVEF-based rather than class-based benefit. The recently published European Society of Cardiology (ESC) guidelines [7] differ only slightly from the AHA/ACC guidelines and recommend CRT in patients in NYHA functional class II, III, or ambulatory IV, with left bundle branch block (LBBB), and QRS duration $\geq 120 \mathrm{~ms}$. In the absence of LBBB, the recommendation class is lowered from I to IIa (QRS > $150 \mathrm{~ms}$ ) or IIb (QRS $120-150 \mathrm{~ms}$ ), reflecting the decreased consensus on the usefulness of the procedure. It is worth noting that these guidelines 
specifically state that LV mechanical dyssynchrony assessed using imaging techniques should not be used for CRT patient selection.

\section{Echocardiographic assessment of dyssynchrony}

Early assessment of dyssynchrony by echocardiography was based on calculations derived from the location of the endocardial surfaces [8]. The advent of pulsed Doppler tissue imaging [or tissue Doppler imaging (TDI)] later provided direct measurement of wall velocity [9], yielding a technique to compare the timing of wall motion across the myocardium. More recently, dyssynchrony assessment based on speckle tracking, both in $2 \mathrm{D}$ and $3 \mathrm{D}$, was developed to increase robustness of the technique by eliminating the dependence of the measurements on the angle of incidence, with the 3D approach also providing insight into LV rotational mechanics $[10,11]$.

Echocardiography, and TDI in particular, had long been the preferred technique for the measurement of dyssynchrony. The PROSPECT trial [12], however, demonstrated that echocardiographically derived dyssynchrony assessment for the purpose of selecting patients for CRT has limited value, with high inter- and intraobserver variability of the measurements suggested as the likely cause. More recently, while the NARROW-CRT trial [13] concluded that patients might benefit from CRT in the presence of marked mechanical dyssynchrony assessed by echocardiography $(n=120)$, the larger Echocardiography Guided Cardiac Resynchronization Therapy multi-center trial (EchoCRT, $n=1,679$ ) attempting to evaluate the effects of CRT on mortality and morbidity of HF patients with echocardiographic evidence of ventricular dyssynchrony was halted due to futility [14].

\section{Magnetic resonance imaging and X-ray computed tomography}

Both cardiac magnetic resonance imaging (CMR) and cardiac X-ray computed tomography (CCT) have been used to assess LV dyssynchrony [15, 16]. Approaches utilizing these modalities have thus far failed to gain widespread acceptance due to the lack of software automation, which leads to higher complexity of the analysis and increased operator bias; they do, however, have the potential for increased clinical use by providing venous anatomy visualization and scar burden assessment, contingent on the development and validation of adequate tools. In one single-center study, CMR regional vector of circumferential strain variance obtained from tagged images predicted response to CRT with sensitivity (Ss) of $76 \%$ and specificity (Sp) of $75 \%$ [17].

For a more complete discussion of the evaluation for CRT using non-echocardiographic techniques, we refer the reader to a recent review [18].

\section{Nuclear medicine}

The assessment of dyssynchrony has long been a part of nuclear cardiology, since work published in 1980 by Links [19] for planar multi-gated radionuclide ventriculography (MUGA). Compared to MUGA and echocardiography, single-photon emission computed tomography (SPECT) and positron emission tomography (PET) are relative newcomers to the dyssynchrony assessment field. ECGgated SPECT has long been used for the assessment of myocardial perfusion and function, principally for the purposes of ischemia detection, coronary artery disease (CAD) identification, infarct characterization, viability assessment, and risk stratification. Similarly, PET and gated PET are widely used to assess myocardial perfusion, function, and viability. The first published description of the use of SPECT to assess LV dyssynchrony by Chen in 2005 [20] built both on myocardial perfusion imaging (MPI) SPECT work by Cooke in 1994 [21] and the technique described by Links for MUGA. More recently, dyssynchrony has also been assessed from gated myocardial PET using both ${ }^{82} \mathrm{Rb}$ perfusion imaging [22] and ${ }^{18} \mathrm{~F}$ fluorodeoxyglucose (FDG) viability imaging [23]. There is also ongoing research into dyssynchrony assessment using gated blood pool SPECT [24-27] and planar MUGA [28], though there are important differences between these nuclear techniques and phase analysis from MPI, as we shall detail later.

Compared to other techniques, MPI benefits from its wide availability and the fact that quantitative analysis tools are well validated, and commonly used for the assessment of perfusion, function, and viability. Three such commercial software packages, QGS+QPS (Cedars-Sinai, Los Angeles, CA) [29], Emory Cardiac Toolbox (Syntermed, Atlanta, GA) [30], and 4DM (Invia, Ann Arbor, MI) [31] all provide functionality to visually and quantitatively characterize the degree of LV dyssynchrony, in addition to quantifying more traditional function parameters such as LV end-diastolic and end-systolic volumes, ejection fraction, and regional wall motion and wall thickening. High automation of the software offers superior reproducibility over software for other modalities by eliminating or reducing operator input [32], which also decreases studyprocessing time. At least one other MPI-based dyssynchrony software (cardioGRAF) is also being developed [33]. This tool evaluates endocardial wall motion dyssynchrony and has seen limited validation. 
Finally, myocardial sympathetic innervation imaging using ${ }^{123}$ I-metaiodobenzylguanidine (MIBG) or ${ }^{11} \mathrm{C}$-epinephrine may offer additional insight. While the prognostic value of the MIBG heart/mediastinum uptake ratio has been shown [34], and it is generally accepted that myocardial innervation improves in responders to CRT [35], the predictive value of baseline innervation for response remains to be demonstrated.

\section{Technical aspects}

The technical description we provide applies to the countbased approach used by Cedars-Sinai's QGS. Emory's SyncTool operates in a similar fashion, though we will indicate differences as appropriate. We refer the reader to another manuscript for a description of dyssynchrony calculations performed by Invia's 4DM [36], which includes thickening and wall motion dyssynchrony calculations.

One of the major advantages of nuclear techniques is that they do not require data acquisition protocol changes for the purpose of being able to perform phase analysis, thus allowing the retrospective processing of studies. SPECT calculations are based on systolic myocardial count increases caused by the partial volume effect [37]—for PET calculations, filtering and isotope-specific processing can be applied to take advantage of the same principles. Count values are extracted for each time interval over the entire myocardium, yielding a unidimensional array for each spatial sampling point. This array represents a timevarying, periodic function from which the first Fourier harmonic (FFH) is determined, the phase angle of which forms the basis of all synchrony measurements (Fig. 1).
The phase and amplitude information can be displayed in polar map fashion either separately, using traditional color mapping, or in combined mode, where color is used to indicate timing (phase angle) and brightness is used to denote the amplitude of variation. The frequency distribution of FFH phase angles is also tabulated in global and regional histograms (Fig. 2), using amplitude information to eliminate phase measurements for which the corresponding amplitude was deemed too low to yield accurate measurements, as the FFH phase angle is essentially illdefined for a signal that exhibits low temporal variations [28]. Histogram metrics are then computed as global and regional measures of dyssynchrony: for global histograms only variability measures are computed, while for regional histograms only means are computed and compared across regions. Variability measures include histogram standard deviation (SD, calculated in the usual fashion for a frequency distribution), bandwidth (BW, the smallest angle range that contains $95 \%$ of the histogram samples), and entropy ( $E$, a variability measure derived from information theory and described in [38], not provided in SyncTool). Because QGS uses filtering and $6^{\circ}$ bins to improve histogram noise characteristics while SyncTool uses $1^{\circ}$ bins and different filter parameters, metrics obtained by both algorithms differ significantly and are not interchangeable.

The use of a single harmonic to describe count variations implies that one angle describes the timing of contraction, whether one chooses the zero-crossing of the harmonic as SyncTool does, or the peak of the harmonic as QGS does (consequently, these two approaches yield reference angles that differ by $90^{\circ}$ ). Another advantage is that acquisitions can consist of any number of frames (usually 8 or 16) without major effect on the calculations-indeed, a

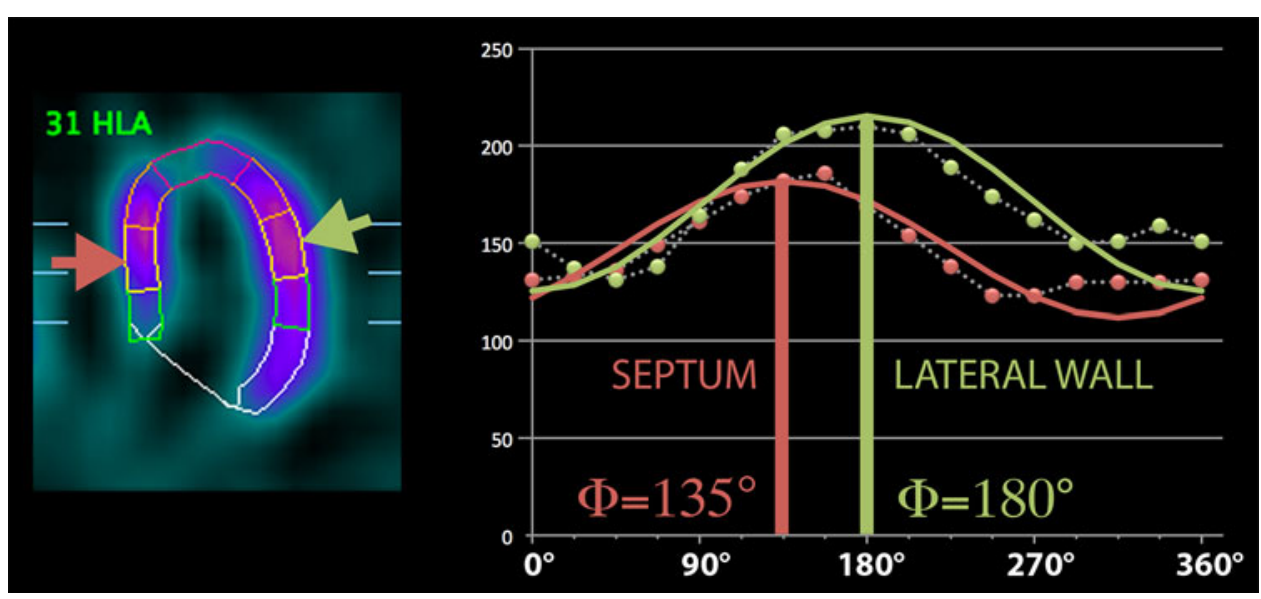

Fig. 1 Count variations in an LBBB patient. The left side shows a typical mid-ventricular end-diastolic horizontal long axis frame of a SPECT MPI study. Two arrows indicate locations on the septum and lateral wall. The right side depicts count variations across the cardiac cycle at the marked locations. The first harmonic curve for each location is superimposed on the counts curve, and the $\mathrm{FFH}$ phase angle is indicated. Note that in this LBBB patient, septal contraction is clearly shown to occur earlier than lateral wall contraction. These calculations are repeated for all myocardial sampling points (color figure online) 


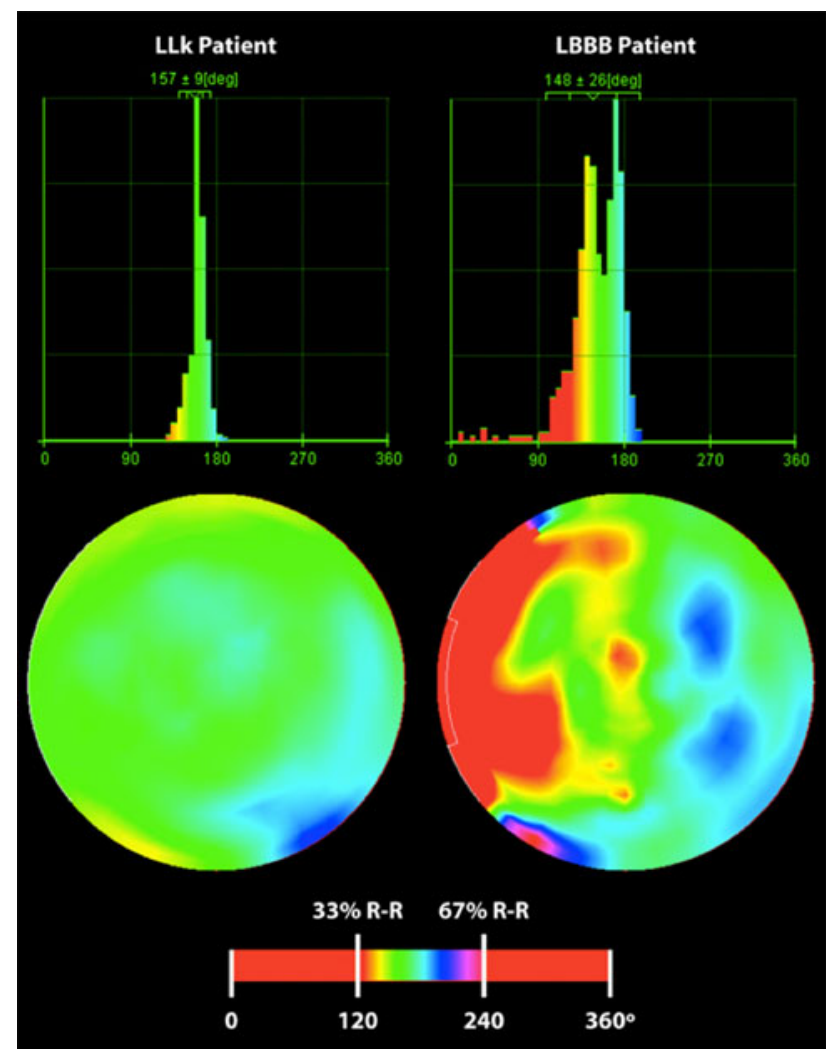

Fig. 2 Comparison of global and regional thickening phase in a normal vs. an LBBB patient. Global histograms (top row) show overall increased dyssynchrony in the patient with LBBB, and polar maps (middle) show uniform contraction for the normal patient and clear septal-to-lateral contraction delay for the patient with LBBB. The color scale used for both patients (bottom) has been adjusted to emphasize contraction timing differences in middle third of $\mathrm{R}-\mathrm{R}$ cycle (deg degrees) [38] (color figure online)

simulation study showed no impact of the number of frames on the quantification of dyssynchrony in SyncTool [39]. Repeatability (variability for repeat studies) and reproducibility (inter- or intra-observer variability for the same study) have been shown to be high, due to the automated nature of the processing [40, 41]. Though there is evidence that camera type and reconstruction methods do not influence dyssynchrony parameters [42, 43], we would recommend caution when applying phase analysis to images obtained using novel acquisition systems, protocols, or imaging agents. In those situations, a comparison showing close similarity of average parameters obtained from a small normal population imaged with the novel approach to published normal limits for the same parameters would suggest that published thresholds can be applied to the new data, though a more extensive analysis would be needed for full validation purposes.

Count-based phase analysis effectively measures the timing of thickening. While QGS and SyncTool use a single harmonic "onset of contraction" definition of timing, other software packages such as 4DM may include different definitions, such as parameters derived from a multi-harmonic "peak of contraction" measurement.

Other nuclear techniques that use blood pool imaging, whether SPECT or planar, perform phase analysis on endocardial wall motion by analyzing count variations throughout the blood pool or near the endocardium. In addition, these techniques can provide inter-ventricular as well as intra-LV dyssynchrony by measuring delays between the left and right ventricle (RV). The technical principles of wall motion phase analysis are the same as those of count-based thickening phase analysis, and usually involve FFH phase analysis, histogram generation, and histogram metrics calculations. Clinical interpretation of wall motion phase analysis results, however, requires bearing in mind that endocardial wall motion is a combination of mid-myocardial motion and myocardial thickening. Endocardial wall motion phase analysis measurements may therefore be affected by factors other than those that affect phase analysis measurements from myocardial thickening alone. This consideration applies to blood pool phase analysis as well as to some of the calculations performed by $4 \mathrm{DM}$ that are derived from wall motion. In a comparison study [44] between 4DM and SyncTool $(n=200$, controls $n=100, \mathrm{LV}$ dysfunction $n=100$ ), the correlation between 4DM endocardial wall motion phase SD and SyncTool phase SD was only moderate $(r=0.55, p<0.0001)$, while correlation between both algorithms was good $(r=0.88, p<0.0001)$ when comparing thickening phase SD.

Of note, though it has been suggested that MPI phase analysis may be susceptible to artifacts in poorly perfused, count-poor myocardial regions [45], a simulation study with SyncTool showed no significant impact on phase measurements in regions with uptake as low as $10 \%$ of normal uptake in other regions [46].

\section{Validation}

The fact that phase analysis dyssynchrony parameters such as histogram SD, BW, and E are somewhat arbitrary concepts designed to represent physiological characteristics, instead of physical measurements like LV cavity volumes, renders validation challenging. Despite intrinsic differences, comparisons to TDI dyssynchrony (delay in peak systolic velocity between the basal septum and the lateral wall) in patients undergoing CRT have shown good agreement for QGS $(n=40$; SD: $r=0.65, p<0.01$; BW: $r=0.69, p<0.01$ [47]) as well as SyncTool $(n=75$; SD: $r=0.80, p<0.0001$; BW: $r=0.89, p<0.0001$ [48]). Good agreement with 3D echocardiography (standard deviation of segmental time to peak systolic velocity) in $\mathrm{HF}$ 
patients was also demonstrated for SyncTool $(n=40$; SD: $r=0.74, p<0.0001$; BW: $r=0.77, p<0.0001$ [49]).

A commonly followed approach has been to confirm that the parameters discriminate as expected between certain patient populations, specifically between normal controls and patients with LBBB (QGS [38], SyncTool SPECT [50, 51], SyncTool PET [22]), right bundle branch block, ventricular paced rhythm, or LV dysfunction (SyncTool SPECT [50, 51]).

\section{CRT and patient selection optimization}

The automated, reproducible nature of phase analysis has led to the suggestion that MPI-derived LV dyssynchrony assessment may play a complementary role to the currently available guidelines [52]. While no multi-center trial has yet been conducted, SPECT phase analysis has been shown to predict response to CRT with good sensitivity and specificity in small patients populations both for QGS $(n=40$, responders $[\mathrm{RSP}]=60 \% ; \mathrm{SD} \mathrm{Ss} / \mathrm{Sp}=83 \% /$ $81 \% ; \mathrm{BW} \quad \mathrm{Ss} / \mathrm{Sp}=83 \% / 81 \%$ [47]) and SyncTool $(n=42, \mathrm{RSP}=71 \% ; \mathrm{SD} \mathrm{Ss} / \mathrm{Sp}=74 \% / 74 \% ; \mathrm{BW} \mathrm{Ss} /$ $\mathrm{Sp}=70 \% / 70 \%$ [53]). Response was defined in both studies as an improvement of 1 or more grades in NYHA functional class at 6-month follow-up. Figure 3 shows an example of differences in baseline dyssynchrony in responder and non-responder patients. It is also possible to detect acute changes in LV dyssynchrony after CRT, and a study evaluating the relationship between acute change and patient outcomes [54] demonstrated that deterioration occurs in a significant number of patients $(n=42$, improved $=41 \%, \quad$ unchanged $=25 \%, \quad$ worsened $=$ $34 \%$ ) and that acute changes can be predicted by an algorithm incorporating the presence of baseline dyssynchrony, myocardial scar burden, and lead concordance (acute improvement or no change in LV synchrony: $\mathrm{Ss} / \mathrm{Sp}=72 \% / 93 \%$, positive predictive value $=96 \%$; deterioration: negative predictive value $=96 \%$ using SyncTool). There is also evidence that myocardial scar burden plays a large part in CRT response, irrespective of LV dyssynchrony: a study investigating the impact of infarct scar burden quantified by rest-redistribution Tl-201 MPI and a summed rest score (SRS) derived using a 17 -segment model $(0=$ normal to $4=$ absence of uptake $)$ on clinical outcomes [55] found that a scar burden $\geq 40 \%$ (SRS $\geq 27$ ) negatively affected CRT response regardless of baseline dyssynchrony measures. The location of myocardial scar had previously been shown to affect response as well [56], with patients without posterolateral scar tissue (assessed by MRI) and severe baseline dyssynchrony (assessed by TDI) showing a response rate of $95 \%$, while patients with a posterolateral scar and/or absent LV dyssynchrony had an $11 \%$ response rate. While there is evidence that transmural scar at the site of $\mathrm{LV}$ pacing prohibits CRT response [57], the effect of non-transmural scar remains unclear [58]. One small study [23] evaluated differences between RSP $(n=7)$ and age- and gendermatched nonresponders (NRSP, $n=7$ ) using ${ }^{18} \mathrm{~F}$ FDG $\mathrm{PET} / \mathrm{CT}$, finding statistically significant differences $(p<0.05)$ both in scar burden (RSP scar $=10 \pm 8 \%$; NRSP scar $=30 \pm 21 \%$ ) and QGS phase entropy (RSP, $E=77 \pm 4 \%$; NRSP, $E=83 \pm 3 \%$ ). There was no association between lead position in viable myocardium and persistent dyssynchrony by echocardiography, but pacemaker leads in all CRT responders were positioned in viable areas. A study in $90 \mathrm{HF}$ patients with SyncTool [59] demonstrated that patients with lead placement concordant with the site of latest mechanical activation had a significantly higher response rate $(n=90$, concordant: $\mathrm{RSP}=79 \%$; discordant: $\mathrm{RSP}=26 \%$ ), exhibiting significant LV systolic function improvement (assessed by echocardiography) at 6-month follow-up, while patients with discordant lead placement showed no significant improvement. To properly account for these factors, a comprehensive approach to CRT patient selection may be needed that combines phase analysis and myocardial scar evaluation, the latter both to assess overall scar burden and to evaluate myocardial viability at possible pacing sites. Patients most likely to respond would also have an LBBB QRS morphology [60] with duration $>150 \mathrm{~ms}$, and nonischemic etiology. A recent study also suggests that within LBBB morphology, distinct activation patterns may have different outcomes [61].

\section{Other clinical applications}

There is evidence that dyssynchrony during the relaxation phase of the LV, which causes LV filling abnormalities, may adversely affect CRT response and long-term clinical outcomes in HF patients [62, 63]. Diastolic dyssynchrony can be readily assessed using a technique similar to systolic dyssynchrony, and is implemented in SyncTool using a multi-harmonic fit of the thickening curve [64]. TDI dyssynchrony (time delays in peak diastolic velocities of LV segments) agrees well with SD and BW from SPECT diastolic phase histograms in HF patients $(n=150$; SD: $r=0.81$; BW: $r=0.75 ; p<0.01$ for both). Diastolic dyssynchrony was also found to be significantly more prevalent than systolic dyssynchrony in patients with endstage renal disease ( $n=121$; prevalence of dyssynchrony: systolic $=47 \%$, diastolic $=65 \%, p<0.0001$ [65]).

Another retrospective study investigated the relation of LV dyssynchrony and cardiovascular events in patients with implantable cardiac defibrillators (ICD) [66], 
Fig. 3 Example of phase analysis using SyncTool in a non-responder (a) and a responder (b) to CRT. a Note the absence of dyssynchrony at baseline, as evidenced by the narrow phase histogram. After 6-month follow-up, no response to CRT was observed, as reflected by deterioration in NYHA functional class from III to IV. In addition, LVEF remained unchanged [baseline (32\%) vs. 6-month follow-up $(33 \%)]$. b In the responder patient, a wide phase histogram indicates the presence of baseline LV dyssynchrony. After 6-month follow-up, this patient improved in NYHA functional class from III to II, indicating response to CRT, and LVEF increased from $27 \%$ at baseline to $33 \%$ at 6-month follow-up [53]
A
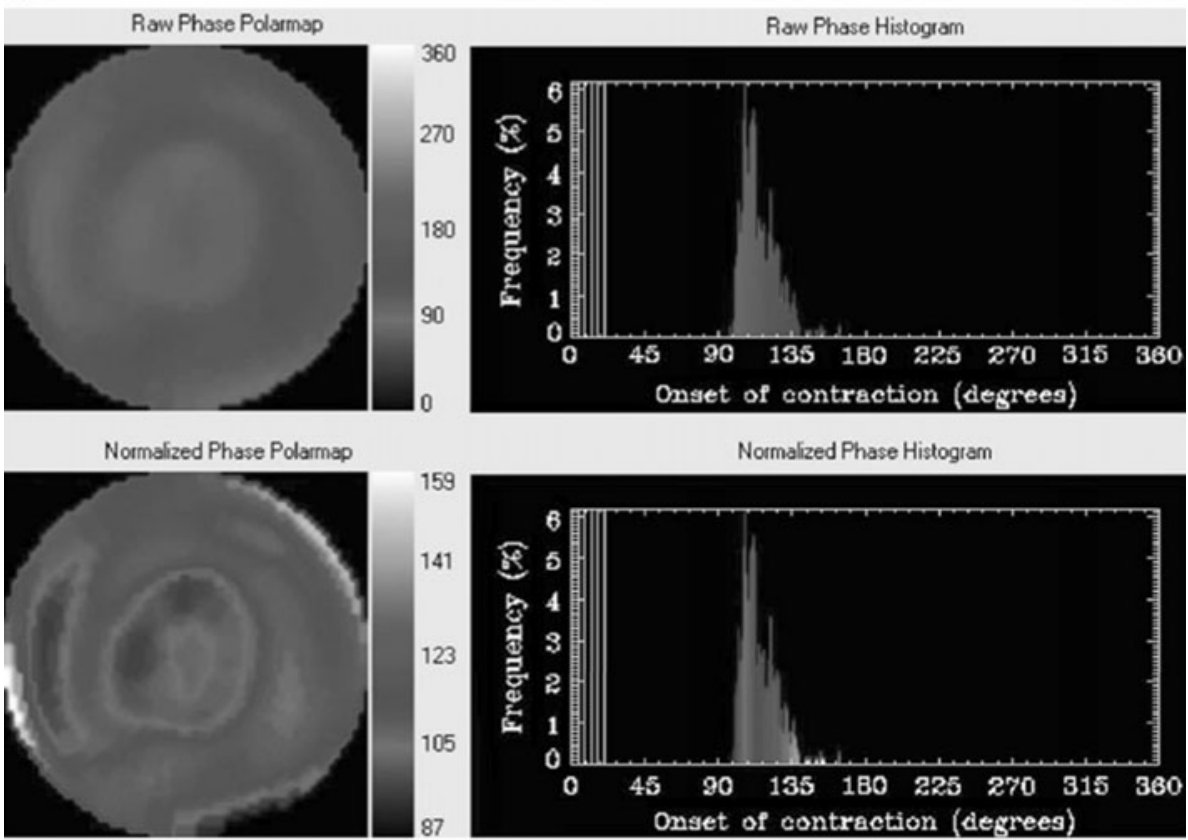

B
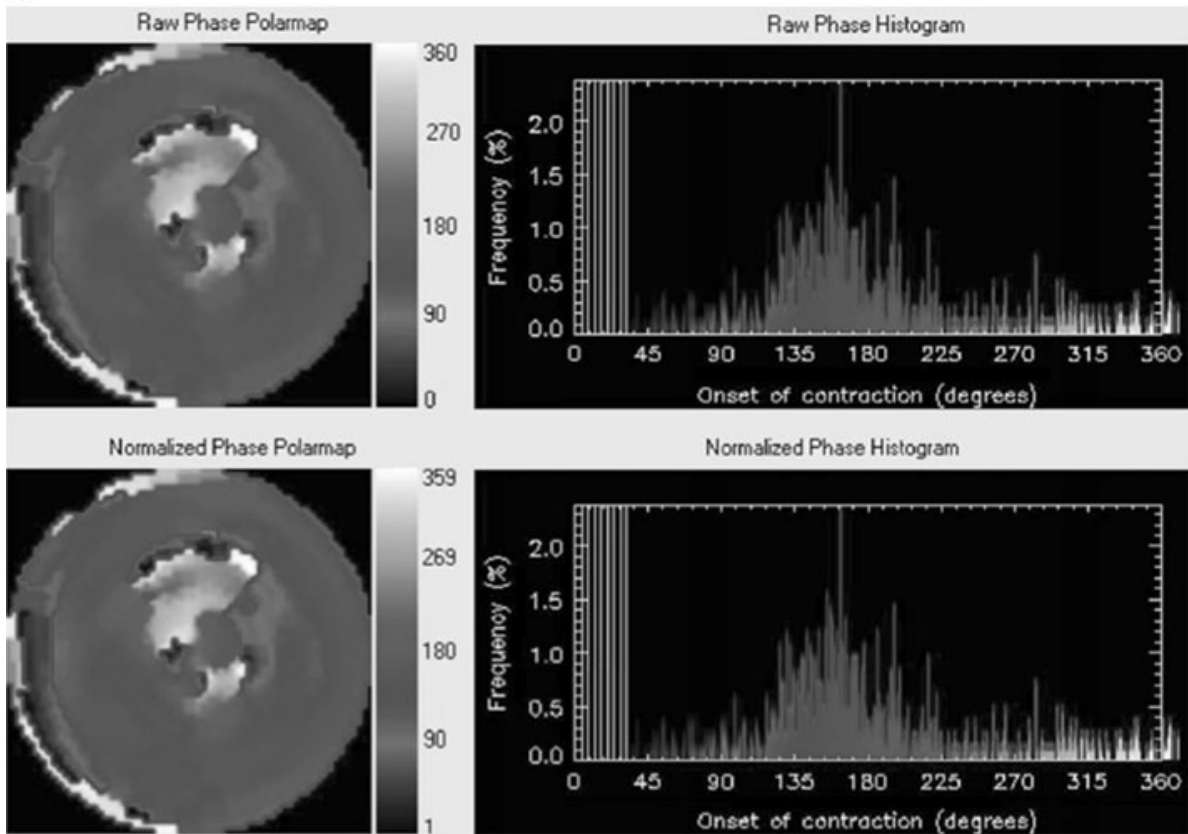

Normalized Phase Histogram

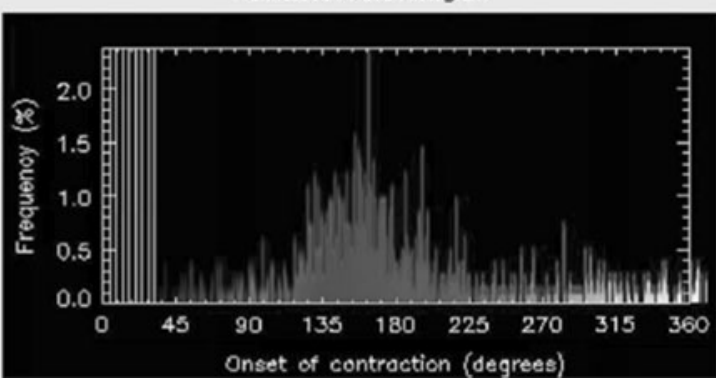

identifying a threshold (SyncTool, $\mathrm{SD}<50^{\circ}$ ) in 70 patients with ICD and LVEF $<40 \%$ below which no events occurred at 1 year, suggesting that presence or absence of dyssynchrony may have long-term outcome implications in such a population.

\section{Conclusions}

Nuclear cardiology provides multiple techniques to assess ventricular dyssynchrony, and MPI phase analysis has recently been the subject of multiple investigations. MPI benefits from high levels of automation and standardization, leading to excellent reproducibility and repeatability, and has the potential to integrate assessment of LV function, viability, baseline dyssynchrony, and optimization of lead placement out of scar tissue and into the area of latest activation, especially in combination with a CCT study providing venous anatomy. Other nuclear techniques (planar or SPECT MUGA) are less automated and have not yet been studied extensively, though it is possible that wall motionderived dyssynchrony may prove valuable by focusing on 
different physiological characteristics of ventricular contraction. MUGA also uniquely provides the ability to assess the relationship between $\mathrm{LV}$ and $\mathrm{RV}$ contraction, though this advantage may disappear with the advent of PET perfusion imaging agents that allow for improved visualization of the RV [67].

CRT patient selection optimization, a key problem in HF treatment, has proven difficult. Wide adoption of MPI dyssynchrony assessment for this purpose is contingent upon the successful completion of a multi-center trial that would evaluate the value of phase analysis, both to determine the amount of dyssynchrony and optimize lead placement, in a manner similar to what the Imaging CRT trial [68] strives to accomplish.

Conflict of interest S.D. Van Kriekinge and G. Germano receive royalties from the licensing of QGS+QPS by Cedars-Sinai Medical Center.

Human and animal studies This article does not contain any studies with human or animal subjects performed by any of the authors.

\section{References}

1. Bader $\mathrm{H}$, Garrigue $\mathrm{S}$, Lafitte $\mathrm{S}$, Reuter $\mathrm{S}$, Jaïs $\mathrm{P}$, Haïssaguerre $\mathrm{M}$, Bonnet J, Clementy J, Roudaut R (2004) Intra-left ventricular electromechanical asynchrony: a new independent predictor of severe cardiac events in heart failure patients. J Am Coll Cardiol 43(2):248-256. doi:10.1016/j.jacc.2003.08.038

2. Lewin JC, May C, Bradfield L, Stewart MD, Fobbs KN, Barrett EA, Wheeler MC, Whitman GR, Taubert KA (2008) ACC/AHA/ HRS 2008 guidelines for device-based therapy of cardiac rhythm abnormalities - a report of the American College of Cardiology/ American Heart Association Task Force on practice guidelines (writing committee to revise the ACC/AHA/NASPE 2002 guideline update for implantation of cardiac pacemakers and antiarrhythmia devices). J Am Coll Cardiol 51(21):E1-E62

3. Abraham WT, Grp MS (2002) Cardiac resynchronization therapy for heart failure-reply. N Engl J Med 347(22):1803-1804

4. Bax JJ, Abraham T, Barold SS, Breithardt OA, Fung JWH, Garrigue S, Gorcsan J, Hayes DL, Kass DA, Knuuti J, Leclercq C, Linde C, Mark DB, Monaghan MJ, Nihoyannopoulos P, Schalij MJ, Stellbrink C, Yu CM (2005) Cardiac resynchronization therapy: Part 1-issues before device implantation. J Am Coll Cardiol 46(12):2153-2167

5. Bax JJ, Abraham T, Barold SS, Breithardt OA, Fung JWH, Garrigue S, Gorcsan J, Hayes DL, Kass DA, Knuuti J, Leclercq C, Linde C, Mark DB, Monaghan MJ, Nihoyannopoulos P, Schalij MJ, Stellbrink C, Yu CM (2005) Cardiac resynchronization therapy: Part 2-issues during and after device. J Am Coll Cardiol 46(12):2168-2182. doi:10.1016/j.jacc.2005.09.020

6. Tracy CM, Epstein AE, Darbar D, DiMarco JP, Dunbar SB, Estes NA 3rd, Ferguson TB Jr, Hammill SC, Karasik PE, Link MS, Marine JE, Schoenfeld MH, Shanker AJ, Silka MJ, Stevenson LW, Stevenson WG, Varosy PD, Ellenbogen KA, Freedman RA, Gettes LS, Gillinov AM, Gregoratos G, Hayes DL, Page RL, Stevenson LW, Sweeney MO (2012) 2012 ACCF/AHA/HRS focused update of the 2008 guidelines for device-based therapy of cardiac rhythm abnormalities: a report of the American College of Cardiology Foundation/American Heart Association Task Force on Practice Guidelines and the Heart Rhythm Society (corrected). Circulation 126(14):1784-1800. doi:10.1161/CIR. 0b013e3182618569

7. Brignole M (2013) 2013 ESC Guidelines on cardiac pacing and cardiac resynchronization therapy: The Task Force on cardiac pacing and resynchronization therapy of the European Society of Cardiology (ESC). Developed in collaboration with the European Heart Rhythm Association (EHRA). Eur Heart J 34(29):22812329. doi:10.1093/eurheartj/eht150

8. Sutton MG, Tajik AJ, Gibson DG, Brown DJ, Seward JB, Guiliani ER (1978) Echocardiographic assessment of left ventricular filling and septal and posterior wall dynamics in idiopathic hypertrophic subaortic stenosis. Circulation 57(3):512520

9. Isaaz K, Thompson A, Ethevenot G, Cloez JL, Brembilla B, Pernot C (1989) Doppler echocardiographic measurement of low velocity motion of the left ventricular posterior wall. Am J Cardiol 64(1):66-75

10. de Isla LP, Balcones DV, Fernandez-Golfin C, Marcos-Alberca P, Almeria C, Rodrigo JL, Macaya C, Zamorano J (2009) Threedimensional-wall motion tracking: a new and faster tool for myocardial strain assessment: comparison with two-dimensionalwall motion tracking. J Am Soc Echocardiogr 22(4):325-330. doi:10.1016/j.echo.2009.01.001

11. Nesser HJ, Winter S (2009) Speckle tracking in the evaluation of left ventricular dyssynchrony. Echocardiogr $\mathrm{J}$ Cardiovasc Ultrasound Allied Techn 26(3):324-336. doi:10.1111/j.15408175.2008.00866.x

12. Chung ES, Leon AR, Tavazzi L, Sun JP, Nihoyannopoulos P, Merlino J, Abraham WT, Ghio S, Leclercq C, Bax JJ, Yu CM, Gorcsan J, Sutton MS, De Sutter J, Murillo J (2008) Results of the predictors of response to CRT (PROSPECT) trial. Circulation 117(20):2608-2616. doi:10.1161/circulationaha.107.743120

13. Muto C, Solimene F, Gallo P, Nastasi M, La Rosa C, Calvanese R, Iengo R, Canciello M, Sangiuolo R, Diemberger I, Ciardiello C, Tuccillo B (2013) A randomized study of cardiac resynchronization therapy defibrillator versus dual-chamber implantable cardioverter-defibrillator in ischemic cardiomyopathy with narrow QRS: the NARROW-CRT Study. Circ Arrhythm Electrophysiol 6(3):538-545. doi:10.1161/circep.113.000135

14. Echocardiography Guided Cardiac Resynchronization Therapy (EchoCRT). US National Institutes of Health. http://clinicaltrials. gov/ct2/show/study/NCT00683696. Accessed June 21, 2013

15. Lardo AC, Abraham TP, Kass DA (2005) Magnetic resonance imaging assessment of ventricular dyssynchrony-current and emerging concepts. J Am Coll Cardiol 46(12):2223-2228. doi:10. 1016/j.jacc.2005.09.015

16. Truong QA, Singh JP, Cannon CP, Sarwar A, Nasir K, Auricchio A, Faletra FF, Sorgente A, Conca C, Moccetti T, Handschumacher M, Brady TJ, Hoffmann U (2008) Quantitative analysis of intraventricular dyssynchrony using wall thickness by multidetector computed tomography. JACC Cardiovasc Imaging 1(6):772-781. doi:10.1016/j.jcmg.2008.07.014

17. Petryka J, Miśko J, Przybylski A, Śpiewak M, Małek ŁA, Werys K, Mazurkiewicz Ł, Gepner K, Croisille P, Demkow M, Rużyłło W (2012) Magnetic resonance imaging assessment of intraventricular dyssynchrony and delayed enhancement as predictors of response to cardiac resynchronization therapy in patients with heart failure of ischaemic and non-ischaemic etiologies. Eur J Radiol 81(10):2639-2647. doi:10.1016/j.ejrad. 2011.10.003

18. AlJaroudi W, Chen J, Jaber WA, Lloyd SG, Cerqueira MD, Marwick T (2011) Nonechocardiographic imaging in evaluation for cardiac resynchronization therapy. Circ Cardiovasc imaging 4(3):334-343. doi:10.1161/circimaging.111.963504 
19. Links JM, Douglass KH, Wagner HN Jr (1980) Patterns of ventricular emptying by Fourier analysis of gated blood-pool studies. J Nucl Med Off Publ Soc Nucl Med 21(10):978-982

20. Chen J, Garcia EV, Folks RD, Cooke CD, Faber TL, Tauxe L, Iskandrian AE (2005) Onset of left ventricular mechanical contraction as determined by phase analysis of ECG-gated myocardial perfusion SPECT imaging: development of a diagnostic tool for assessment of cardiac mechanical dyssynchrony. J Nucl Cardiol 12(6):687-695. doi:10.1016/j.nuclcard.2005.06.088

21. Cooke CD, Garcia EV, Cullom SJ, Faber TL, Pettigrew RI (1994) Determining the accuracy of calculating systolic wall thickening using a Fast Fourier-Transform approximation-a simulation study based on canine and patient data. J Nucl Med 35(7): 1185-1192

22. Cooke CD, Esteves FP, Chen J, Garcia EV (2011) Left ventricular mechanical synchrony from stress and rest Rb-82 PET myocardial perfusion ECG-gated studies: differentiating normal from LBBB patients. J Nucl Cardiol 18(6):1076-1085. doi:10. 1007/s12350-011-9455-Z

23. Uebleis C, Ulbrich M, Tegtmeyer R, Schuessler F, Haserueck N, Siebermair J, Becker C, Nekolla S, Cumming P, Bartenstein P, Kaab S, Hacker M (2011) Electrocardiogram-gated F-18-FDG PET/CT hybrid imaging in patients with unsatisfactory response to cardiac resynchronization therapy: initial clinical results. J Nucl Med 52(1):67-71. doi:10.2967/jnumed.110.078709

24. Lalonde M, Birnie D, Ruddy TD, deKemp RA, Wassenaar RW (2010) SPECT blood pool phase analysis can accurately and reproducibly quantify mechanical dyssynchrony. J Nucl Cardiol 17(5):803-810. doi:10.1007/s12350-010-9231-5

25. Somsen GA, Verberne HJ, Burri H, Ratib O, Righetti A (2006) Ventricular mechanical dyssynchrony and resynchronization therapy in heart failure: a new indication for Fourier analysis of gated blood-pool radionuclide ventriculography. Nucl Med Commun 27(2):105-112

26. Van Tosh A, Nichols KJ, Goldman M, Muratore K, Palestro CJ, Reichek N (2012) Right to left ventricular apical contraction interval - a new index of ventricular dyssynchrony derived from SPECT gated blood pool radionuclide ventriculography. J Am Coll Cardiol 59(13):E1179-E1179

27. Vilain D, Daou D, Casset-Senon D, Faraggi M, Le Guludec D (2001) Optimal 3-dimensional method for right and left ventricular Fourier phase analysis in electrocardiography-gated bloodpool SPECT. J Nucl Cardiol 8(3):371-378

28. O'Connell JW, Schreck C, Moles M, Badwar N, DeMarco T, Olgin J, Lee B, Tseng Z, Kumar U, Botvinick EH (2005) A unique method by which to quantitate synchrony with equilibrium radionuclide angiography. J Nucl Cardiol 12(4):441-450

29. Germano G, Kavanagh PB, Slomka PJ, Van Kriekinge SD, Pollard G, Berman DS (2007) Quantitation in gated perfusion SPECT imaging: The Cedars-Sinai approach. J Nucl Cardiol 14(4):433-454

30. Garcia EV, Faber TL, Cooke CD, Folks RD, Chen J, Santana C (2007) The increasing role of quantification in clinical nuclear cardiology: the Emory approach. J Nucl Cardiol 14(4):420-432

31. Ficaro EP, Lee BC, Kritzman JN, Corbett JR (2007) Corridor4DM: the Michigan method for quantitative nuclear cardiology. J Nucl Cardiol 14(4):455-465. doi:10.1016/j.nuclcard.2007. 06.006

32. Germano G, Kavanagh PB, Slomka PJ, Berman DS (2012) Tracking a therapeutic response: how reliable are serial measurements of LV perfusion and function? J Nucl Cardiol 19(2):360-363. doi:10.1007/s12350-012-9518-9

33. Yamamoto A, Takahashi N, Munakata K, Hosoya T, Shiiba M, Okuyama T, Abe K, Kaneshiro T, Tsuruta H, Takama T, Sato M (2007) Global and regional evaluation of systolic and diastolic left ventricular temporal parameters using a novel program for
ECG-gated myocardial perfusion SPECT-validation by comparison with gated equilibrium radionuclide angiography and speckle-tracking radial strain from echocardiography. Ann Nucl Med 21(2):115-121

34. Jacobson AF, Senior R, Cerqueira MD, Wong ND, Thomas GS, Lopez VA, Agostini D, Weiland F, Chandna H, Narula J (2010) Myocardial Iodine-123 meta-iodobenzylguanidine imaging and cardiac events in heart failure results of the Prospective ADMIRE-HF (AdreView Myocardial Imaging for Risk Evaluation in Heart Failure) Study. J Am Coll Cardiol 55(20): 2212-2221. doi:10.1016/j.jacc.2010.01.014

35. Scholtens AM, Braat AJ, Tuinenburg A, Meine M, Verberne HJ (2013) Cardiac sympathetic innervation and cardiac resynchronization therapy. Heart failure reviews. doi:10.1007/s10741-0139400-0

36. van der Veen BJ, Al Younis I, Ajmone-Marsan N, Westenberg JJM, Bax JJ, Stokkel MPM, de Roos A (2012) Ventricular dyssynchrony assessed by gated myocardial perfusion SPECT using a geometrical approach: a feasibility study. Eur J Nucl Med Mol Imaging 39(3):421-429. doi:10.1007/s00259-011-1991-x

37. Mazziotta JC, Phelps ME, Plummer D, Kuhl DE (1981) Quantitation in positron emission computed tomography: 5. Physicalanatomical effects. J Comput Assist Tomogr 5(5):734-743

38. Van Kriekinge SD, Nishina H, Ohba M, Berman DS, Germano G (2008) Automatic global and regional phase analysis from gated myocardial perfusion SPECT imaging: application to the characterization of ventricular contraction in patients with left bundle branch block. J Nucl Med 49(11):1790-1797

39. Chen J, Faber TL, Cooke CD, Garcia EV (2008) Temporal resolution of multiharmonic phase analysis of ECG-gated myocardial perfusion SPECT studies. J Nucl Cardiol 15(3):383-391

40. Trimble MA, Velazquez EJ, Adams GL, Honeycutt EF, Pagnanelli RA, Barnhart HX, Chen J, Iskandrian AE, Garcia EV, Borges-Neto S (2008) Repeatability and reproducibility of phase analysis of gated single-photon emission computed tomography myocardial perfusion imaging used to quantify cardiac dyssynchrony. Nucl Med Commun 29(4):374-381

41. Van Kriekinge S, Otaki Y, Alexanderson E, Hernandez S, Canseco N, Jimenez M, Meave A, Berman D, Germano G (2012) Repeatability of left ventricular dyssynchrony measurements: impact of parameter dependence on histogram shape. J Nucl Med Meeting Abstracts 53(1_MeetingAbstracts):1861-

42. Li DF, Zhou YL, Feng JL, Yuan DL, Cao KJ, Garcia EV, Chen J (2009) Impact of image reconstruction on phase analysis of ECGgated myocardial perfusion SPECT studies. Nucl Med Commun 30(9):700-705. doi:10.1097/MNM.0b013e32832ad83d

43. Pazhenkottil AP, Buechel RR, Herzog BA, Nkoulou RN, Valenta I, Fehlmann U, Ghadri JR, Wolfrum M, Husmann L, Kaufmann PA (2010) Ultrafast assessment of left ventricular dyssynchrony from nuclear myocardial perfusion imaging on a new high-speed gamma camera. Eur J Nucl Med Mol Imaging 37(11):2086-2092. doi:10.1007/s00259-010-1507-0

44. AlJaroudi W, Jaber WA, Grimm RA, Marwick T, Cerqueira MD (2012) Alternative methods for the assessment of mechanical dyssynchrony using phase analysis of gated single photon emission computed tomography myocardial perfusion imaging. Int $\mathrm{J}$ Cardiovasc Imaging 28(6):1385-1394. doi:10.1007/s10554-0119963-6

45. Botvinick EH, O'Connell JW, Badhwar N (2009) Imaging synchrony. J Nucl Cardiol 16(6):846-848. doi:10.1007/s12350-0099151-4

46. Cheung A, Zhou YL, Faber TL, Garcia EV, Zhu L, Chen J (2012) The performance of phase analysis of gated SPECT myocardial perfusion imaging in the presence of perfusion defects: a simulation study. J Nucl Cardiol 19(3):500-506. doi:10.1007/s12350011-9494-5 
47. Boogers MM, Van Kriekinge SD, Henneman MM, Ypenburg C, Van Bommel RJ, Boersma E, Dibbets-Schneider P, Stokkel MP, Schalij MJ, Berman DS, Germano G, Bax JJ (2009) Quantitative gated SPECT-derived phase analysis on gated myocardial perfusion SPECT detects left ventricular dyssynchrony and predicts response to cardiac resynchronization therapy. J Nucl Med 50(5):718-725. doi:10.2967/jnumed.108.060657

48. Henneman MM, Chen J, Ypenburg C, Dibbets P, Bleeker GB, Boersma E, Stokkel MP, van der Wall EE, Garcia EV, Bax JJ (2007) Phase analysis of gated myocardial perfusion single-photon emission computed tomography compared with tissue Doppler imaging for the assessment of left ventricular dyssynchrony. J Am Coll Cardiol 49(16):1708-1714. doi:10.1016/j.jacc.2007.01.063

49. Marsan NA, Henneman MM, Chen J, Ypenburg C, Dibbets P, Ghio S, Bleeker GB, Stokkel MP, van der Wall EE, Tavazzi L, Garcia EV, Bax JJ (2008) Left ventricular dyssynchrony assessed by two three-dimensional imaging modalities: phase analysis of gated myocardial perfusion SPECT and tri-plane tissue Doppler imaging. Eur J Nucl Med Mol Imaging 35(1):166-173. doi:10. 1007/s00259-007-0539-6

50. Chen J, Henneman MM, Trimble MA, Bax JJ, Borges-Neto S, Iskandrian AE, Nichols KJ, Garcia EV (2008) Assessment of left ventricular mechanical dyssynchrony by phase analysis of ECGgated SPECT myocardial perfusion imaging. J Nucl Cardiol 15(1):127-136

51. Nichols KJ, Van Tosh A, Siddiqi S, Chen J, Garcia EV, Palestro CJ, Reichek N (2009) Gated myocardial perfusion SPECT asynchrony measurements in patients with left bundle branch block. Int J Cardiovasc Imaging 25(1):43-51. doi:10.1007/ s10554-008-9354-9

52. Chen J, Bax JJ, Henneman MM, Boogers MJ, Garcia EV (2008) Is nuclear imaging a viable alternative technique to assess dyssynchrony? Europace 10:101-105. doi:10.1093/europace/eun221

53. Henneman MM, Chen J, Dibbets-Schneider P, Stokkel MR, Bleeker GB, Ypenburg C, van der Wall EE, Schalij MJ, Garcia EV, Bax JJ (2007) Can LV dyssynchrony as assessed with phase analysis on gated myocardial perfusion SPECT predict response to CRT? J Nucl Med 48(7):1104-1111

54. Friehling M, Chen J, Saba S, Bazaz R, Schwartzman D, Adelstein EC, Garcia E, Follansbee W, Soman P (2011) A prospective pilot study to evaluate the relationship between acute change in left ventricular synchrony after cardiac resynchronization therapy and patient outcome using a single-injection gated SPECT protocol. Circ Cardiovasc Imaging 4(5):532-539. doi:10.1161/circimaging. 111.965459

55. Adelstein EC, Tanaka H, Soman P, Miske G, Haberman SC, Saba SF, Gorcsan J (2011) Impact of scar burden by single-photon emission computed tomography myocardial perfusion imaging on patient outcomes following cardiac resynchronization therapy. Eur Heart J 32(1):93-103. doi:10.1093/eurheartj/ehq389

56. Bleeker GB, Kaandorp TAM, Lamb HJ, Boersma E, Steendijk P, de Roos A, van der Wall EE, Schalij MJ, Bax JJ (2006) Effect of posterolateral scar tissue on clinical and echocardiographic improvement after cardiac resynchronization therapy. Circulation 113(7):969-976. doi:10.1161/circulationaha.105.543678

57. Ypenburg C, Schalij MJ, Bleeker GB, Steendijk P, Boersma E, Dibbets-Schneider P, Stokkel MP, van der Wall EE, Bax JJ (2007) Impact of viability and scar tissue on response to cardiac resynchronization therapy in ischaemic heart failure patients. Eur Heart J 28(1):33-41. doi:10.1093/eurheartj/eh1379

58. Duggirala S, Lee BK (2013) Optimizing cardiac resynchronization therapy for congestive heart failure. Curr Probl Cardiol 38(6):215-237. doi:10.1016/j.cpcardiol.2013.03.003
59. Boogers MJ, Chen J, van Bommel RJ, Borleffs CJW, DibbetsSchneider P, van der Hiel B, Al Younis I, Schalij MJ, van der Wall EE, Garcia EV, Bax JJ (2011) Optimal left ventricular lead position assessed with phase analysis on gated myocardial perfusion SPECT. Eur J Nucl Med Mol Imaging 38(2):230-238. doi:10.1007/s00259-010-1621-z

60. Zareba W, Klein H, Cygankiewicz I, Hall WJ, McNitt S, Brown M, Cannom D, Daubert JP, Eldar M, Gold MR, Goldberger JJ, Goldenberg I, Lichstein E, Pitschner H, Rashtian M, Solomon S, Viskin S, Wang P, Moss AJ (2011) Effectiveness of cardiac resynchronization therapy by QRS morphology in the Multicenter Automatic Defibrillator Implantation Trial-Cardiac Resynchronization Therapy (MADIT-CRT). Circulation 123(10):10611072. doi:10.1161/circulationaha. 110.960898

61. Sohal M, Shetty A, Duckett S, Chen Z, Sammut E, Amraoui S, Carr-White G, Razavi R, Rinaldi CA (2013) Noninvasive assessment of LV contraction patterns using CMR to identify responders to CRT. JACC Cardiovasc Imaging 6(8):864-873. doi:10.1016/j.jcmg.2012.11.019

62. Schuster I, Habib G, Jego C, Thuny F, Avierinos JF, Derumeaux G, Beck L, Medail C, Franceschi F, Renard S, Ferracci A, Lefevre J, Luccioni R, Deharo JC, Djiane P (2005) Diastolic asynchrony is more frequent than systolic asynchrony in dilated cardiomyopathy and is less improved by cardiac resynchronization therapy. J Am Coll Cardiol 46(12):2250-2257. doi:10.1016/ j.jacc.2005.02.096

63. Waggoner AD, Rovner A, de las Fuentes L, Faddis MN, Gleva MJ, Sawhney N, Davila-Roman VG (2006) Clinical outcomes after cardiac resynchronization therapy: importance of left ventricular diastolic function and origin of heart failure. $\mathrm{J}$ Am Soc Echocardiogr 19(3):307-313. doi:10.1016/j.echo.2005.10. 014

64. Boogers MJ, Chen J, Veltman CE, van Bommel RJ, Mooyaart EAQ, Al Younis I, van der Hiel B, Dibbets-Schneider P, van der Wall EE, Schalij MJ, Garcia EV, Bax JJ, Delgado V (2011) Left ventricular diastolic dyssynchrony assessed with phase analysis of gated myocardial perfusion SPECT: a comparison with tissue Doppler imaging. Eur J Nucl Med Mol Imaging 38(11): 2031-2039. doi:10.1007/s00259-011-1870-5

65. Chen J, Kalogeropoulos AP, Verdes L, Butler J, Garcia EV (2011) Left-ventricular systolic and diastolic dyssynchrony as assessed by multi-harmonic phase analysis of gated SPECT myocardial perfusion imaging in patients with end-stage renal disease and normal LVEF. J Nucl Cardiol 18(2):299-308. doi:10. 1007/s12350-010-9331-2

66. AlJaroudi WA, Hage FG, Hermann D, Doppalapudi H, Venkataraman R, Heo J, Iskandrian AE (2010) Relation of left-ventricular dyssynchrony by phase analysis of gated SPECT images and cardiovascular events in patients with implantable cardiac defibrillators. J Nucl Cardiol 17(3):398-404. doi:10.1007/ s12350-009-9169-7

67. Berman DS, Germano G, Slomka PJ (2012) Improvement in PET myocardial perfusion image quality and quantification with flurpiridaz F 18. J Nucl Cardiol 19:S38-S45. doi:10.1007/s12350011-9487-4

68. Sommer A, Kronborg MB, Poulsen SH, Bottcher M, Norgaard BL, Bouchelouche K, Mortensen PT, Gerdes C, Nielsen JC (2013) Empiric versus imaging guided left ventricular lead placement in cardiac resynchronization therapy (ImagingCRT): study protocol for a randomized controlled trial. Trials 14. doi:10. 1186/1468-6708-14-113 